Research Article

\title{
Application of a Bentonite Slurry Modified by Polyvinyl Alcohol in the Cutoff of a Landfill
}

\author{
Guozhong Dai $\mathbb{D}^{1},{ }^{1}$ Yanmin Sheng $\mathbb{D}^{1},{ }^{1}$ Yutao Pan $\mathbb{D}^{2},{ }^{2}$ Guicai Shi $\mathbb{D}^{1},{ }^{1}$ and Shujin Li $\mathbb{D}^{1}$ \\ ${ }^{1}$ School of Civil Engineering and Architecture, Changzhou Institute of Technology, Changzhou 213032, China \\ ${ }^{2}$ Department of Civil \& Environmental Engineering, National University of Singapore, 1 Engineering Drive 2, 119576, Singapore
}

Correspondence should be addressed to Yutao Pan; ceepany@nus.edu.sg

Received 7 August 2019; Revised 3 December 2019; Accepted 20 December 2019; Published 13 January 2020

Academic Editor: Eric Lui

Copyright ( $\odot 2020$ Guozhong Dai et al. This is an open access article distributed under the Creative Commons Attribution License, which permits unrestricted use, distribution, and reproduction in any medium, provided the original work is properly cited.

Soil-bentonite cutoff walls are usually used to contain the contaminants of landfills. The pumpability, permeability, and adsorption capability of the slurry are all crucial to the performance of the cutoff wall. In this study, the effect of polyvinyl alcohol (PVA) was used to improve the performance of bentonite slurry. A series of lab tests were conducted to evaluate the pumpability, permeability, and adsorption capacity with different concentrations of PVA treatment. Results show that the addition of PVA can increase the fluidity and pumpable period of slurry, which facilitates the casting and grouting during construction. The addition of PVA also helps to reduce the permeability coefficient of slurry and improve the adsorption capability which enhances the cutoff performance of the walls.

\section{Introduction}

At present, landfills are the main disposal method for municipal solid waste, accounting for $88 \%$ and $80 \%$ of terminal disposal quantity in China and America, respectively. Leachate is one of the main pollutants of landfills, which may easily migrate to an adjacent area. Considering the multiple hazardous constituents included in the landfill, leakage of the leachate could cause major environmental or ecological problems [1].

Leakage of hazardous leachate usually involves fermentation, rain wash, and soaking of surface water or ground water [2]. The main factors affecting the output of leachate include precipitation, infiltration of surface water, sheltering conditions, hydrogeological conditions, and roof design of landfill [3]. The leachate in landfills often includes a high concentration of chemical oxygen demand (CODcr), biology oxygen demand (BOD5), heavy metal ions, and ammonia nitrogen, all of which have significant pollution potentials.

An example of leachate composition in the Jiashan landfill in Changzhou (China) is shown in Tables 1 and 2. In this landfill, the leachates from nine sites were selected, and their physical properties and components were evaluated. As can be observed, the range of the composition is very wide, indicating a highly variable concentration and similar findings available in several studies [4-6]. Landfill leachate will corrode the impervious layer of the landfill and then enter the ground to form a highly polluted aquifer, which will affect the surrounding geological environment. At the same time, the pollution will enter the surrounding soil and rivers with the complex groundwater system which is difficult to be considered and traced. And it will seriously affect the surrounding environment. Especially in mountainous cities, landfills are more likely to cause environmental pollution in low-lying areas due to the high-altitude difference. Xie et al. [7-10] evaluated the distribution of landfill leachate in Suzhou and Huainan (China) and concluded that the advection and mechanical dispersion are the major means of contaminant migration in these landfills. It contributes to the evaluation of the construction of low permeability cutoff walls and permeable reactive barriers.

Vertical cutoff walls are usually used to impede the horizontal migration of the leachate [11-14]. Backfills with low permeability (e.g., soil-bentonite slurry and cement- 
TABle 1: Physical properties of leachate.

\begin{tabular}{lccc}
\hline Physical property & Index & Physical property & Index \\
\hline Color & Yellow-dark gray-purple black & Organic acid $(\mathrm{mg} / \mathrm{L})$ & $50-25000$ \\
Smell & Stink & pH & $5.2-8.5$ \\
Total residue $(\mathrm{mg} / \mathrm{L})$ & $2300-36000$ & Total hardness & $3000-10000$ \\
Conductivity $(\mu \Omega / \mathrm{cm})$ & $10-26000$ & Oxidation-reduction potential $(\mathrm{mV})$ & $320-800$ \\
\hline
\end{tabular}

TABle 2: Composition of leachate.

\begin{tabular}{|c|c|c|c|}
\hline Composition & Range & Physical property & Range \\
\hline Chemical oxygen demand $\left(\mathrm{COD}_{\mathrm{cr}}\right)(\mathrm{mg} / \mathrm{L})$ & $500-85000$ & Suspended solids (SS) (mg/L) & $200-1000$ \\
\hline Total organic carbon $(\mathrm{TOC})(\mathrm{mg} / \mathrm{L})$ & $1500-22000$ & Total phosphorus (TP) (mg/L) & $0.8-72$ \\
\hline Biology oxygen demand (BOD5) (mg/L) & $50-19000$ & $\mathrm{SO}^{4-}(\mathrm{mg} / \mathrm{L})$ & $10-750$ \\
\hline $\mathrm{NH}^{3-}-\mathrm{N}(\mathrm{mg} / \mathrm{L})$ & $20-7400$ & $\mathrm{Cl}^{-}(\mathrm{mg} / \mathrm{L})$ & $180-3250$ \\
\hline
\end{tabular}

bentonite slurry) are usually used to fill preexcavated trenches to form continuous barriers. The performance of the cutoff wall is significantly affected by the quality control during installation $[15,16]$. The permeability of the bentonite is required to be less than $1 \times 10^{-9} \mathrm{~m} / \mathrm{s}[17,18]$. On the other hand, the pumpability is also very important as it affects the workability of bentonite which also influences the quality of slurry wall.

Additives were frequently utilised to improve the performance of the bentonite slurry wall. Guler et al. [19] used an ionic polymer to modify bentonite to prepare a soilbentonite material and measured its permeability coefficient. It was found that the permeability coefficient of the material first decreases with the content of ionic polymer and then remains the same when the content of ionic polymer exceeds $2 \%$. Yang et al. [20] modified calcium bentonite with sodium hexametaphosphate to improve pumpability during construction. Norris et al. [21] used modified bentonite and hard water (high calcium content) to prepare the filling of soilbentonite cutoff walls, showing that high water hardness has an adverse effect on reducing the permeability of the slurry. Wang et al. [22] found that loess-modified bentonite can greatly improve the adsorption capacity of $\mathrm{Pb}$ (II).

To date, most studies are focused on only one aspect of the slurry (e.g., pumpability, permeability coefficient, or adsorption effect). In fact, a slurry with all three aspects improved is more advantageous when used as a cutoff material. In this study, bentonite slurry is modified by polyvinyl alcohol (PVA), which is an organic polymer material with a strong adsorption effect on heavy metal ions and organic matter $[23,24]$. PVA facilitates the dispersion of bentonite slurry [25]. This helps to improve the homogeneity of the slurry and hence the overall cutoff performance of the cutoff wall [14]. PVA was found to be able to coat the surface of the grains, increasing the adsorption capability and reducing the permeability of the slurry [26]. The addition of PVA into bentonite was found to increase the specific surface area of bentonite particles and enhance the adsorption capacity [27]. PVA was found to be able to reduce the porosity and homogenize the spatial distribution of porosity [28], both of which are very important in reducing the permeability of the material. The pumpability is first examined to ensure the workability during the construction stage. Then, the permeability coefficient and adsorption capability are examined.

\section{Methodology}

2.1. Reagent and Materials. The raw materials include sodium bentonite, ordinary Portland cement (OPC), fly ash, polyvinyl alcohol (PVA), and sodium carbonate solution, as shown in Table 3. The OPC and fly ash were used because the fly ash consists of fine particles rich in aluminum oxide $\left(\mathrm{Al}_{2} \mathrm{O}_{3}\right)$ and silicon dioxide $\left(\mathrm{SiO}_{2}\right)$, which would facilitate a pozzolanic reaction with calcium hydroxide generated by hydration of the cement. On top of that, PVA was used to modify the physical properties of the bentonite slurry, as will be shown later. It has the idealized formula $\left[\mathrm{CH}_{2} \mathrm{CH}(\mathrm{OH})\right]_{n}$, and its molecular weight is 1700 . It is a nontoxic, watersoluble synthetic polymer. The PVA is flammable and irritant which will be harmful to humans after absorption. Sodium carbonate was used to make the bentonite slurry more dispersible and hence more homogeneous and stable. The source and other details of the materials are summarized in Table 4.

2.2. Sample Preparation. Bentonite powder was first mixed with distilled water using a machinery mixer for five minutes to ensure homogeneity of the bentonite slurry with a water content of $30 \%$. Then, the bentonite slurry was mixed with PVA and $0.15 \%$ sodium carbonate solution for one hour so that the PVA could infiltrate the bentonite colloid [29]. Sodium carbonate was used to ensure that the calcium bentonite could be transferred into sodium bentonite, and the $\mathrm{pH}$ of the mixture was higher than 12 . The sodium ions facilitate dispersion of the bentonite, homogenizing the slurry. The alkaline environment ensures the hydration of cement and the occurrence of pozzolanic reactions afterwards. Then, the modified bentonite was mixed with cement and fly ash for 10 minutes so that the mixture was sufficiently homogeneous, and the mixture was cast before the setting time of the cement, at which the mixture starts to harden $[30,31]$. The mass ratio of cement, bentonite, and fly ash was 
TABLE 3: The amount of each slurry component.

\begin{tabular}{lcccccc}
\hline No. & Cement (\%) & Bentonite (\%) & Fly ash (\%) & PVA (\%) & $\mathrm{Na}_{2} \mathrm{CO}_{3}(\%)$ & Water $(\%)$ \\
\hline A0 & 14.60 & 13.67 & 13.14 & 0 & 0.15 & 58.44 \\
A1 & 14.60 & 13.67 & 13.14 & 0.11 & 0.15 & 58.33 \\
A2 & 14.60 & 13.67 & 13.14 & 0.15 & 0.15 & 58.29 \\
A3 & 14.60 & 13.67 & 13.14 & 0.19 & 0.15 & 58.25 \\
A4 & 14.60 & 13.67 & 13.14 & 0.23 & 58.21 \\
\hline
\end{tabular}

TABle 4: Details of materials.

\begin{tabular}{lcc}
\hline Materials & Details & Producer \\
\hline $\begin{array}{l}\text { Sodium bentonite } \\
\text { Ordinary Portland cement }\end{array}$ & 75um sieve residue less than 2.5\% & Nanjing Tangshang Pengruntu Co., Ltd \\
Fly ash & Grade 42.5 & Jinfeng Cement \\
Polyvinyl alcohol & Grade I & Jiangsu Huadian Qishuyan Power Generation Co., \\
Sodium carbonate solution & Model 1688 & Ltd \\
\hline
\end{tabular}

fixed at $14.6 \%, 13.67 \%$, and $13.14 \%$, respectively, to ensure the pumpability of slurry for 40 minutes after mixing. The pumpable period is reduced with higher cement content and fly ash. A sufficient pumpable period is crucial for construction because it allows the slurry to be grouted into the ground before hardening.

After mixing, the viscous slurry was cast into cylindrical specimens $100 \mathrm{~mm}$ in height and $50 \mathrm{~mm}$ in diameter and cured in distilled water at room temperature for 28 days. Five mix ratios with different PVA contents were used, and three specimens were cast for each mix ratio. The compositions of the mix ratios are listed in Table 3.

2.3. Fluidity Test. The pumpability can be evaluated by fluidity test according to the standard for evaluation of the fluidity of cement slurry (GB/T8077 2012). This is different from ANSI/API SPECIFICATION 10A, which takes thickening time to evaluate the pumpability of slurry. The pumpable period was evaluated with a fluidity meter consisting of a fluidity pan and a truncated cone. The main test apparatus is as follows.

Metal truncated cone circular die $(\phi 36 \times 60 \times 60)$ : upper diameter of $36 \mathrm{~mm}$, lower diameter of $60 \mathrm{~mm}$, and height of $60 \mathrm{~mm}$ with smooth and seamless inner walls.

Plastic fluidity pan: $500 \mathrm{~mm}$ in diameter and $5 \mathrm{~mm}$ in thickness with concentric circles of different diameters on the surface. The test apparatus is shown in Figure 1.

The test procedures are as follows:

(1) Place the fluidity pan in a horizontal position and clean the fluidity pan and truncated cone with a wet cloth to make its surface wet without water stains and place the truncated cone in the center of the fluidity pan.

(2) Inject the mixed slurry into the truncated cone and scrape with a spatula. The truncated cone is lifted vertically, upon which the time is started. Thirty seconds later, two mutually perpendicular diameters of the expanded slurry were measured and the

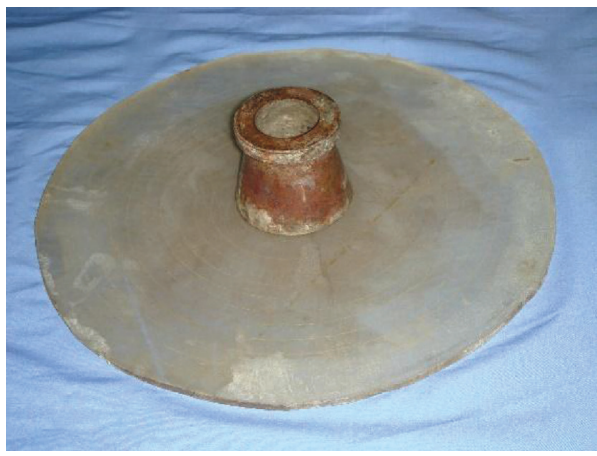

FIGURE 1: Fluidity meter.

average value $(\mathrm{mm})$ was taken as the fluidity of the slurry.

(3) Measure the fluidity of the slurry every 5 minutes as the last step, until the fluidity of the pulp reaches $140 \mathrm{~mm}$. The duration for the fluidity to drop to $140 \mathrm{~mm}$ is the pumpable period of the slurry.

2.4. Infiltration Test. The slurry permeability coefficients with different curing periods were tested using GDS equipment with a fully automatic and triaxial permeation system (PERM). The slurry permeability refers to the ability to make the fluid pass through without damaging the medium structure after the slurry is cured for certain time. The schematic diagram is shown in Figure 2.

Before the infiltration test, the vacuum saturator is used to saturate the sample so that the saturation of the sample for test is not less than 95\%. During the test, purified water is used as osmotic fluid. The samples were first saturated in a vacuum chamber. They were then laterally wrapped up by a flexible membrane which would stick to the side faces during the test. A cell pressure of $200 \mathrm{kPa}$ was applied. This amounts to the confining pressure of slurry at a depth of $15 \mathrm{~m}$, which is at the middle level of a typical cutoff wall. The infiltration hydraulic pressure was $100 \mathrm{kPa}$, which is equivalent to a 


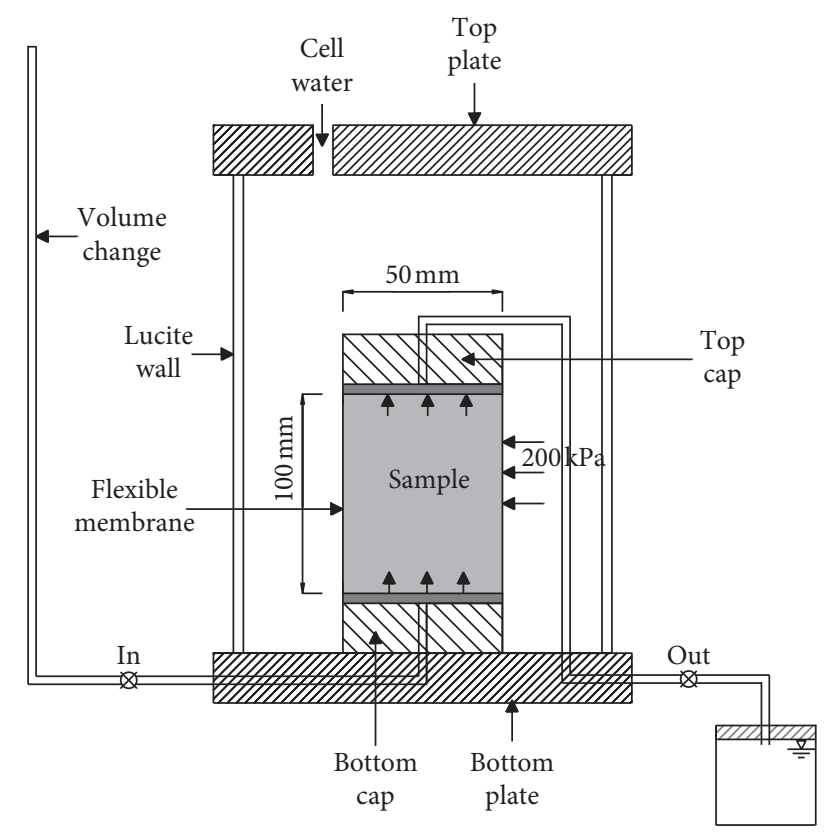

FIGURE 2: Schematic equipment diagram.

water head difference of $10 \mathrm{~m}$. With the hydration and pozzolanic reaction of the cement and fly ash in the sample, an unconfined compressive strength of at least $200 \mathrm{kPa}$ was reached before the test. The elastic modulus is approximately 100 300 times the unconfined compressive strength [32]. Hence, the volume change is continuously measured by an automatic volume change meter. Three samples were tested for each mix ratio, and the relative difference should not exceed $10 \%$ to ensure the consistency of results. from

The permeability coefficient of slurry can be evaluated

$$
\begin{aligned}
& k=\frac{\left(V_{2}-V_{1}\right)}{i A\left(t_{2}-t_{1}\right)}, \\
& i=\frac{P}{\gamma_{w} h},
\end{aligned}
$$

where $k$ is the permeability coefficient $(\mathrm{m} / \mathrm{s}) ; V_{1}$ and $V_{2}$ are the initial and ending volumes reading, respectively; $t_{1}$ and $t_{2}$ are the start and ending times; $h$ is the height of the samples; $A$ is the cross-sectional area of the sample; $i$ is the hydraulic gradient; $P$ is the pressure difference between the two ends of the sample; and $\gamma_{w}$ is the unit weight of water.

\subsection{Evaluation of Kinetic Adsorption Effect. Figure 3 shows} the equipment used for evaluation of the adsorption effect. The sample (diameter $=100 \mathrm{~mm}$; length $=50 \mathrm{~mm}$ ) was mounted in the chamber with its surrounding sealed by a stainless steel material. $250 \mathrm{~mm}$ artificial leachate was input into the liquid storage chamber from the opening. Then, a constant air pressure of $100 \mathrm{kPa}$ was applied on top of the leachate until all the leachate was exhausted. The compositions of artificial leachate are listed in Table 5. It is colorless and tasteless. In addition, the $\mathrm{pH}$ of artificial leachate is 4.1 .

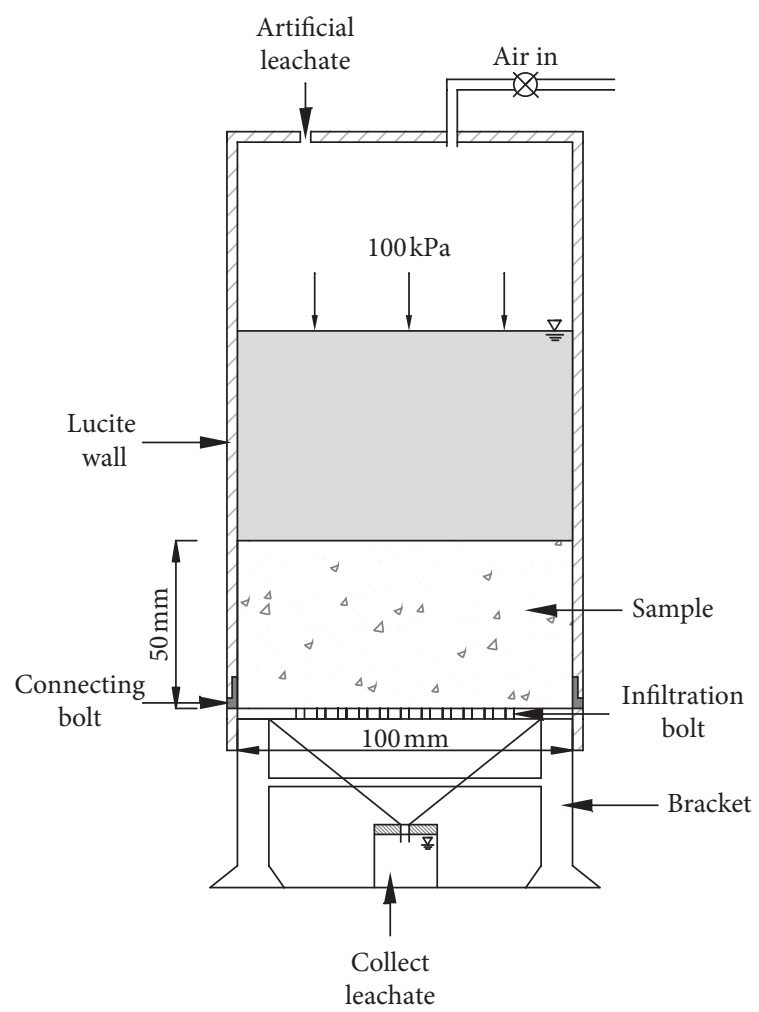

Figure 3: Schematic diagram for the artificial leachate permeation test.

TABle 5: Compositions of artificial leachate.

\begin{tabular}{lc}
\hline Composition & Content $(\mathrm{mg} / \mathrm{L})$ \\
\hline $\mathrm{NH}_{4}-\mathrm{N}^{5}$ & 1333 \\
$\mathrm{COD}_{\mathrm{cr}}{ }^{6}$ & 13333 \\
$\mathrm{BOD}_{5}{ }^{6}$ & 6000 \\
Total $\mathrm{Hg}^{7}$ & 1.3 \\
Total $\mathrm{Pb}^{7}$ & 20 \\
\hline
\end{tabular}

Note. The concentration of $\mathrm{NH}_{4}-\mathrm{N}$ was measured by the low concentration nitrogen oxide detector. The concentration of $\mathrm{COD}_{\mathrm{cr}}$ and $\mathrm{BOD}_{5}$ was measured by liquid chromatograph. The concentration of total $\mathrm{Hg}$ and total $\mathrm{Pb}$ was measured by the atomic absorption spectrophotometer. The instrument details are listed in Table 6.

The output leachate was collected, and then the concentration of the output leachate was evaluated. After the bromine ion penetration test, the sample was diluted 10 times with the aforementioned landfill leachate which was used to measure the migration rate of components of the leachate. Due to the different proportions of slurry, there are some differences in the migration delay factors of components in the leachate among the samples. The delay factor $R_{d}$ can be evaluated from

$$
R_{d}=\frac{v_{g w}}{v_{s p}}
$$

where $v_{g w}$ is the average velocity of water flow $(\mathrm{cm} / \mathrm{s})$ and $v_{s p}$ is the migration velocity of pollutants $(\mathrm{cm} / \mathrm{s})$ [33]. The concentrations of the components in leachate were measured by an atomic absorption spectrophotometer (AA300). 
TABLE 6: Details of testing instrument.

\begin{tabular}{lccc}
\hline No. & Instrument & Type & Producer \\
\hline 1 & Truncated cone & $\Phi 36 * 60 * 60 \mathrm{~mm}$ & Hangzhou Keran Experimental Instruments Co., Ltd \\
2 & Fluidity pan & $\Phi 500 * 5 \mathrm{~mm}$ & Hangzhou Keran Experimental Instruments Co., Ltd \\
3 & Fully automatic and triaxial permeation system & PERM & British GDS \\
4 & Artificial leachate permeation test & $\Phi 100 * 50 \mathrm{~mm}$ & Self-made \\
5 & Low concentration nitrogen oxide detector & $42-$ DNMSDAB & Thermo Scientific \\
6 & Liquid chromatograph & LC-20A & Shimadzu Corporation of Japan \\
7 & Atomic absorption spectrophotometer & AA300 & Analytik Jena AG \\
\hline
\end{tabular}

2.6. Scanning Electron Microscopy Imaging Details. The sample surface was cleaned and then dried in an oven under $105^{\circ} \mathrm{C}$ for 8 hours. The substances (e.g., calcium hydroxide, $\mathrm{CSH}$, and $\mathrm{CASH}$ ) after curing have very high melting point, and little reaction would occur under $105^{\circ} \mathrm{C}$ for 8 hours. Hence, the drying process would not change the physical composition. The dried samples were sealed and preserved for SEM test. The conductive adhesives were adhered to the sample bench, a small amount of dried samples were fixed on the conductive adhesives, and then the excess samples which were not adhered to the conductive adhesives were removed. Due to the poor conductivity of cement, bentonite, and other substances, gold powder was sprayed on the sample surface. After the sample was installed, the SEM test was carried out to observe the micromorphology of the slurry. The source and details of the testing instrument are summarized in Table 6.

\section{Results and Discussion}

3.1. Fluidity and Pumpable Period. Fluidity is a significant indicator of pumpability. Table 7 shows the initial fluidity and pumpable period of the slurry. The results show that the initial fluidity and pumpable period increase with an increase in PVA. The pumpable period is extended because the PVA coats the surface of the cement, retarding the hydration reaction, which serves to harden the slurry in a short period [28]. This is consistent with SEM images that the grains without PVA (Figure 4) are relatively smooth, while the grains with $0.19 \%$ PVA (Figure 5(a)) are wrapped up with corrugations. A possible reason for the increase in the initial fluidity of the sample with an increased amount of PVA is that the soft coating on the surface of the grains serves to reduce friction and isolate the hard grains.

The fluidity test results show that the inclusion of PVA helps extend the pumpable period, in which contractors can have sufficient time to cast cutoff structures. This potentially helps improve workmanship and homogeneity of the slurry wall, which is crucial to the cutoff performance of the cutoff walls $[14,34,35]$.

3.2. Permeability Coefficient. Table 8 shows that the permeability coefficients of slurry under different curing periods decrease with time. This is consistent with a previous study on cement-treated soils (e.g., $[36,37]$ ). This is mainly due to the hydration and pozzolanic reaction, which is gradually mobilized over time. The products of the pozzolanic reaction are calcium silicate hydrate $(\mathrm{CSH})$ and calcium aluminum silicate hydrate (CASH), which are deposited onto clustered clay particles, and hence decrease the pore size [36]. Moreover, the expanded bentonite in water may fill the pores inside the slurry and further reduce the permeability coefficient [38]. The reaction procedures are shown in Figure 6 . The permeability coefficient reaches a stable value after 28 days, and little reduction is observed after that.

As shown in Figure 5(a), very few calcium hydroxide planar crystal units were observed and the fly ash spheres were largely wrapped up by corrugations. On the 14th day, the planar calcium hydroxide crystals grew with hydration (Figure 5(b)). However, on the 28th day, fewer planar crystals of calcium hydroxide were discernible, and the pores were filled with new cylindrical crystals of $\mathrm{CSH}$ or CASH. This implies that the calcium hydroxide generated by the cement hydration reacted with the silicon and aluminum minerals in the fly ash. The pore size of the 28-day sample decreased. This is consistent with the decrease in permeability coefficient.

Figure 7 shows a significant reduction in the permeability coefficient with the addition of PVA. However, when the PVA content is higher than $0.2 \%$, the permeability coefficient increases. The existence of PVA promotes hydration of the cement [28], which facilitates the filling of the pores during hydration and the subsequent pozzolanic reactions. The most optimized PVA content is $0.18 \%$, and the permeability coefficient is only $2 \%$ of that of the slurry without PVA. However, the reason why using 0.19\% PVA yields the lowest permeability remains unclear.

3.3. Adsorption Effect. Table 9 shows that the pollutant concentration of output leachate is significantly reduced with addition of PVA. The $\mathrm{pH}$ of output leachate is 7.2 7.8, which is close to neutral value. This means that the slurry has a strong adsorption on acids. With the incorporation of $\mathrm{PVA}$, the concentration of $\mathrm{NH}_{4}-\mathrm{N}, \mathrm{COD}_{\mathrm{Cr}}, \mathrm{BOD}_{5}$, and other components in the leachate collected after the adsorption test decreased significantly. Comparing the components of the leachate before and after the test, it can be known that the slurry has good adsorption on $\mathrm{NH}_{4}-\mathrm{N}, \mathrm{COD}_{\mathrm{Cr}}$ and $\mathrm{BOD}_{5}$. The concentration of heavy metal ions in the collected leachate can hardly be detected (adsorption rate was close to $100 \%)$ while the PVA was added. This implicates the slurry added with PVA has excellent performance on adsorption of heavy metal ions. The slurry with a PVA content of $0.19 \%$ 
TABLE 7: Results of slurry fluidity and pumpable period.

\begin{tabular}{lcc}
\hline Number & Initial fluidity $F_{0}(\mathrm{~mm})$ & Pumpable period (min) \\
\hline A0 & 150 & 15 \\
A1 & 175 & 55 \\
A2 & 180 & 65 \\
A3 & 190 & 85 \\
A4 & 195 & 95 \\
\hline
\end{tabular}

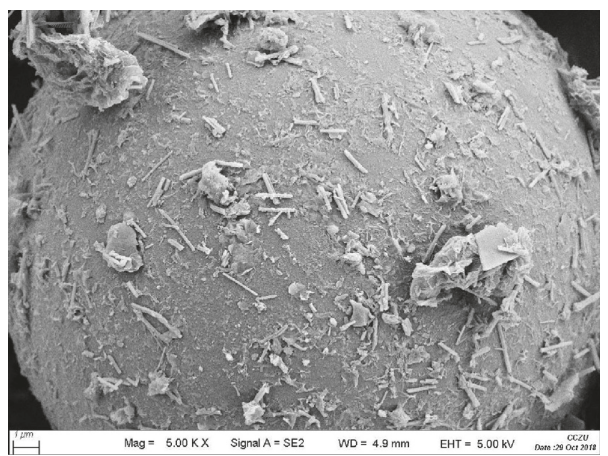

FIGURE 4: SEM image of bentonite slurry without PVA (no. A0 in Table 9, curing period=7 days).

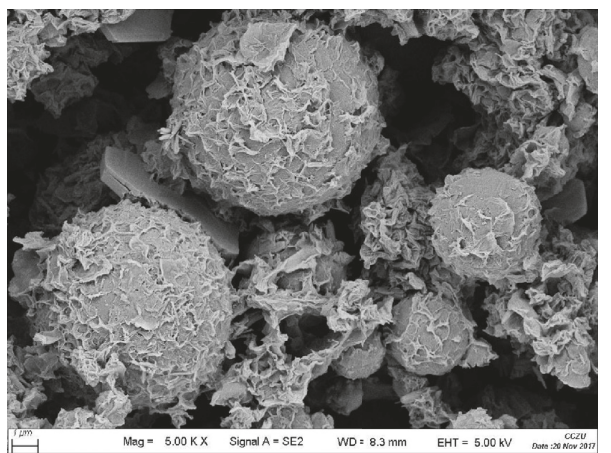

(a)

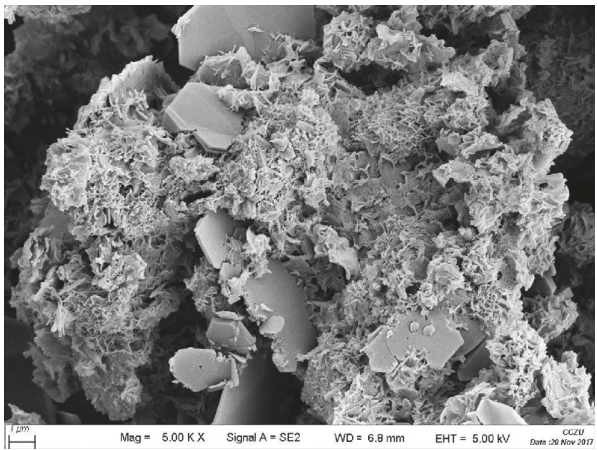

(b)

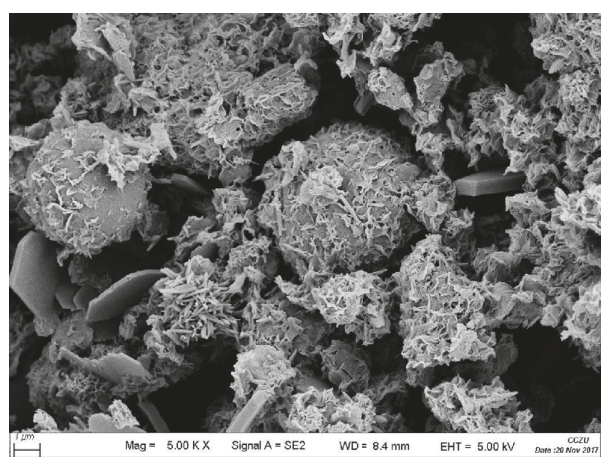

(c)

Figure 5: SEM image of bentonite slurry modified by $0.19 \%$ PVA (no. A3 in Table 9): (a) curing period = 7 days; (b) curing period = 14 days; (c) curing period $=28$ days.

shows the lowest output concentration of pollutants. This implies that a PVA content of $0.19 \%$ has the highest adsorption capability.

From Table 10, it can be seen that the delay factors of $\mathrm{COD}_{\mathrm{cr}}$ and $\mathrm{BOD}_{5}$ migration in different samples are relatively small, ranging from 4.78 to 5.43 and 6.86 to 7.27 , respectively, while the delay factors of migration to $\mathrm{NH}_{4}-\mathrm{N}$ are relatively large, ranging from 25.24 to 25.96 . It can be seen that PBFC slurry has a better retardation effect on $\mathrm{NH}_{4}$ $\mathrm{N}$ compared with $\mathrm{COD}_{\mathrm{cr}}$ and $\mathrm{BOD}_{5}$. In addition, compared 
TABLe 8: Permeability coefficient under different curing periods.

\begin{tabular}{ccccccccc}
\hline No. & $\begin{array}{c}7 \mathrm{~d} \\
\left(10^{-8} \mathrm{~cm} / \mathrm{s}\right)\end{array}$ & $\begin{array}{c}14 \mathrm{~d} \\
\left(10^{-8} \mathrm{~cm} / \mathrm{s}\right)\end{array}$ & $\begin{array}{c}21 \mathrm{~d} \\
\left(10^{-8} \mathrm{~cm} / \mathrm{s}\right)\end{array}$ & $\begin{array}{c}28 \mathrm{~d} \\
\left(10^{-8} \mathrm{~cm} / \mathrm{s}\right)\end{array}$ & $\begin{array}{c}35 \mathrm{~d} \\
\left(10^{-8} \mathrm{~cm} / \mathrm{s}\right)\end{array}$ & $\begin{array}{c}42 \mathrm{~d} \\
\left(10^{-8} \mathrm{~cm} / \mathrm{s}\right)\end{array}$ & $\begin{array}{c}49 \mathrm{~d} \\
\left(10^{-8} \mathrm{~cm} / \mathrm{s}\right)\end{array}$ & $\begin{array}{c}56 \mathrm{~d} \\
\left(10^{-8} \mathrm{~cm} / \mathrm{s}\right)\end{array}$ \\
\hline A0 & 115.3 & 47.1 & 35.7 & 20.3 & 20.3 & 20.3 & 20.3 & 19.5 \\
A1 & 106.2 & 45.1 & 26.1 & 10.7 & 10.7 & 10.6 & 10.6 \\
A2 & 90.5 & 30.3 & 15.6 & 2.4 & 2.3 & 2.3 & 2.3 & 2.6 \\
A3 & 85.4 & 15.7 & 6.8 & 0.7 & 0.6 & 0.6 & 0.5 \\
A4 & 90.3 & 10.3 & 4.3 & 2.6 & 2.5 & 2.4 & 2.4 \\
\hline
\end{tabular}

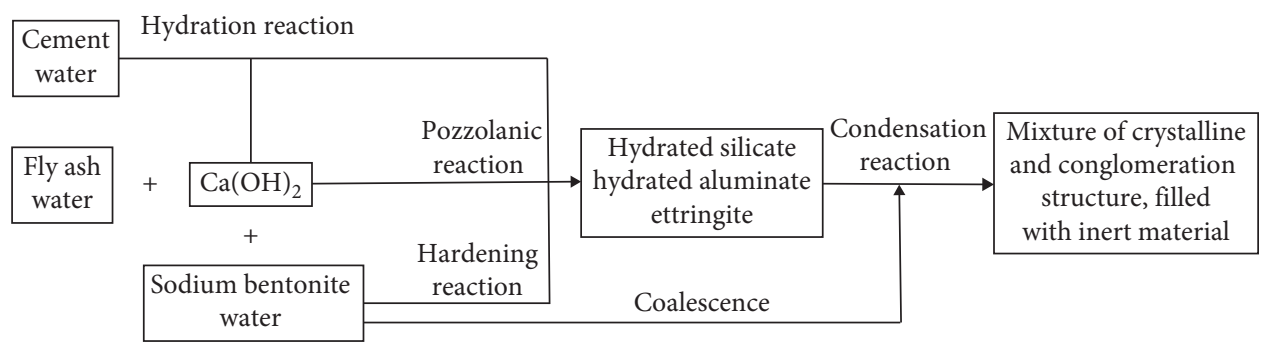

FIGURE 6: Reaction procedures during slurry preparation.

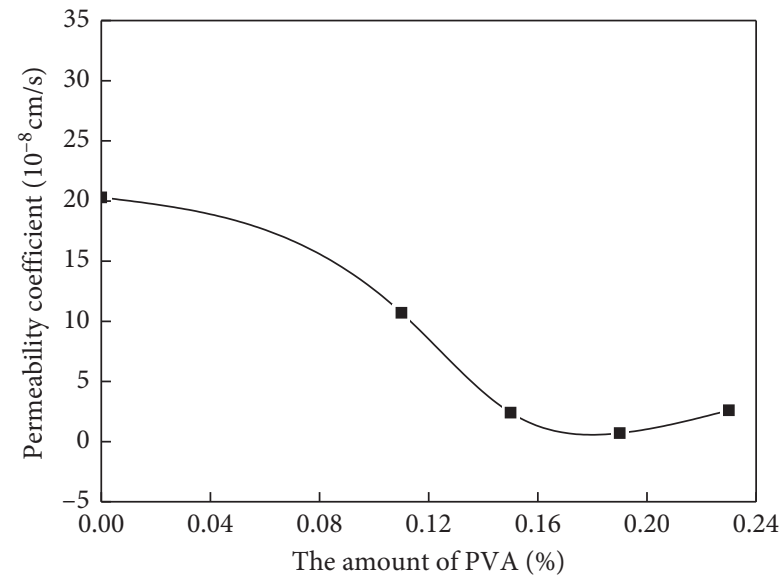

Figure 7: 28-day Permeability coefficient with different amounts of PVA.

TABLE 9: Output leachate pollutant concentrations.

\begin{tabular}{|c|c|c|c|c|c|}
\hline Composition & A0 (mg/L) & A1 $(\mathrm{mg} / \mathrm{L})$ & $\mathrm{A} 2(\mathrm{mg} / \mathrm{L})$ & $\mathrm{A} 3(\mathrm{mg} / \mathrm{L})$ & A4 $(\mathrm{mg} / \mathrm{L})$ \\
\hline $\mathrm{NH}_{4}-\mathrm{N}^{5}$ & 563.3 & 346.1 & 278.2 & 172.1 & 193.2 \\
\hline $\mathrm{COD}_{\mathrm{cr}}{ }^{6}$ & 305.1 & 183.2 & 150.5 & 90.3 & 136.4 \\
\hline $\mathrm{BOD}_{5}^{6}$ & 50.2 & 31.5 & 20.3 & 18.7 & 23.6 \\
\hline Total $\mathrm{Hg}^{7}$ & 0.03 & 0 & 0 & 0 & 0 \\
\hline Total $\mathrm{Pb}^{7}$ & 0.08 & 0.03 & 0 & 0.02 & 0 \\
\hline
\end{tabular}

TABLE 10: Results of transport parameters of $\mathrm{COD}_{\mathrm{cr}}$, BOD5, and $\mathrm{NH}_{4}-\mathrm{N}$.

\begin{tabular}{lccc}
\hline Number & $\mathrm{COD}_{\mathrm{cr}}$ & $\mathrm{BOD}_{5}$ & $\mathrm{NH}_{4}-\mathrm{N}$ \\
\hline $\mathrm{A} 0$ & 4.78 & 6.86 & 25.24 \\
$\mathrm{~A} 1$ & 5.26 & 7.10 & 25.79 \\
$\mathrm{~A} 2$ & 5.39 & 7.25 & 25.64 \\
$\mathrm{~A} 3$ & 5.27 & 7.22 & 25.86 \\
$\mathrm{~A} 4$ & 5.43 & 7.27 & 25.95 \\
\hline
\end{tabular}

with the experimental data of $\mathrm{A} 0$ and others, it can be seen that the retardation effect of slurry with PVA is better. The slurry can improve the blocking effect of $\mathrm{COD}_{\mathrm{Cr}}, \mathrm{BOD}_{5}$, and $\mathrm{NH}_{4}-\mathrm{N}$ in leachate.

As shown in the SEM images in Figures 5(a)-5(c), the slurry with PVA shows highly corrugated layers outside the particles, thus increasing the specific area and hence the adsorption capability. The existence of PVA also promotes the pozzolanic reaction [28], which generates small crystals 
and further increases the specific surface area of the material, as seen in Figure 5(c).

On the other hand, the hydrogen bonding effect of the hydroxyl group of PVA to NH4-N has a good chemical adsorption effect [39]. This chemical adsorption effect is potentially stronger than the physical adsorption discussed above.

The mechanism of adsorption and retardation of $\mathrm{NH}_{4}-\mathrm{N}$ is as follows. Firstly, there are alcohol hydroxyl groups in PVA, which will form hydrogen bond with $\mathrm{NH}_{4}-\mathrm{N}$, and the adsorption effect of antiseepage slurry is better under the effect of hydrogen bond [40]. Secondly, the modified bentonite transforms from calcium bentonite to sodium bentonite, and the ion exchange and expansion of bentonite are better which enhance the adsorption of $\mathrm{NH}_{4}-\mathrm{N}$.

The mechanism of adsorption and retardation of CODcr and $\mathrm{BOD}_{5}$ is as follows. Firstly, PVA itself has a strong adsorption capacity for organics. Secondly, the hydroxyl group in PVA enters the bentonite space through ion exchange, replacing the exchangeable cation between montmorillonite layers so as to enlarge the space between the inner layer of the bentonite. The adsorption ability for $\mathrm{COD}_{\mathrm{cr}}$ and $\mathrm{BOD}_{5}$ has been enhanced because of the increase of bentonite specific surface area.

In addition, during the adsorption test, the heavy metal ions moved from the leachate to the surface of the bentonite through the sweeping action of PVA molecules and then were adsorbed to the surface of the modified bentonite through the electrostatic attraction of the clay particles. The cations adsorbed on the surface of the modified bentonite particles were then exchanged with the heavy metal ions in that the adsorption ability of antiseepage slurry for heavy metal ions was enhanced [41].

\section{Conclusion}

The effect of PVA on the pumpability, permeability, and adsorption capability of bentonite slurry was investigated. It was found that the addition of PVA helps extend the fluidity and pumpable period of the slurry, reducing the permeability coefficient and enhancing the adsorption capability of the bentonite slurry. The optimal PVA content is approximately $0.19 \%$; higher concentrations do not show evident improvement. With this improvement, the modified bentonite slurry is potentially more workable, impermeable, and adsorptive.

\section{Data Availability}

The data used to support the findings of this study are included within the article.

\section{Conflicts of Interest}

The authors declare that they have no conflicts of interest.

\section{Acknowledgments}

The National Natural Science Foundation of China (no. 51678083) is gratefully acknowledged.

\section{References}

[1] H. Xie, H. Yan, S. Feng, Q. Wang, and P. Chen, “An analytical model for contaminant transport in landfill composite liners considering coupled effect of consolidation, diffusion, and degradation," Environmental Science and Pollution Research, vol. 23, no. 19, pp. 19362-19375, 2016.

[2] G. Mondelli, H. L. Giacheti, and J. A. Howie, "Interpretation of resistivity piezocone tests in a contaminated municipal solid waste disposal site," Geotechnical Testing Journal, vol. 33, no. 2, pp. 1-14, 2010.

[3] C. P. Lin, S. H. Tang, and C. C. Chung, "Development of TDR penetrometer through theoretical and laboratory investigations:1. Measurement of soil dielectric permittivity," Geotechnical Testing Journal, vol. 29, no. 4, pp. 1-8, 2006.

[4] P.-J. He, X. Qu, L.-M. Shao, G.-J. Li, and D.-J. Lee, "Leachate pretreatment for enhancing organic matter conversion in landfill bioreactor," Journal of Hazardous Materials, vol. 142, no. 1-2, pp. 288-296, 2007.

[5] M. S. Hossain, M. A. Gabr, and M. A. Barlaz, "Relationship of compressibility parameters to municipal solid waste decomposition," Journal of Geotechnical and Geoenvironmental Engineering, vol. 129, no. 12, pp. 1151-1158, 2003.

[6] M. S. Hossain, K. K. Penmethsa, and L. Hoyos, "Permeability of municipal solid waste in bioreactor landfill with degradation," Geotechnical and Geological Engineering, vol. 27, no. 1, pp. 43-51, 2009.

[7] H.-J. Xie, Y.-M. Chen, L.-T. Zhan et al., "Investigation of migration of pollutant at the base of Suzhou Qizishan landfill without a liner system," Journal of Zhejiang University-Science $A$, vol. 10, no. 3, pp. 439-449, 2009.

[8] H. Ke, C. Zhang, M. Sedighi, H. R. Thomas, and Y. Chen, "An analytical model for diffusion of chemicals under thermal effects in semi-infinite porous media," Computers and Geotechnics, vol. 69, pp. 329-337, 2015.

[9] H. Xie, Y. Chen, H. R. Thomas, M. Sedighi, S. A. Masum, and Q. Ran, "Contaminant transport in the sub-surface soil of an uncontrolled landfill site in China: site investigation and twodimensional numerical analysis," Environmental Science and Pollution Research, vol. 23, no. 3, pp. 2566-2575, 2016.

[10] H. Xie, S. Wang, Y. Chen, J. Jiang, and Z. Qiu, "An analytical model for contaminant transport in cut-off wall and aquifer system," Environmental Geotechnics, vol. 10, pp. 1-10, 2018.

[11] Y.-J. Du, M.-L. Wei, K. R. Reddy, F. Jin, H.-L. Wu, and Z.-B. Liu, "New phosphate-based binder for stabilization of soils contaminated with heavy metals: leaching, strength and microstructure characterization," Journal of Environmental Management, vol. 146, pp. 179-188, 2014.

[12] E. Koda and P. Osinski, "Bentonite cut-off walls: solution for landfill remedial works," Environmental Geotechnics, vol. 4, no. 4, pp. 223-232, 2016.

[13] Y. Pan, Y. Liu, J. Hu, M. Sun, and W. Wang, "Probabilistic investigations on the watertightness of jet-grouted ground considering geometric imperfections in diameter and position," Canadian Geotechnical Journal, vol. 54, no. 10, pp. 1447-1459, 2017.

[14] Y. Pan, Y. Liu, and E. J. Chen, "Probabilistic investigation on defective jet-grouted cut-off wall with random geometric imperfections," Géotechnique, vol. 69, no. 5, pp. 420-433, 2019.

[15] P. Castaldo, F. Jalayer, and B. Palazzo, "Probabilistic assessment of groundwater leakage in diaphragm wall joints for deep excavations," Tunnelling and Underground Space Technology, vol. 71, pp. 531-543, 2018. 
[16] Y. I. Koh, "The study on cutting-off the leachate leakage or infiltration from waste landfill by wall mass constructed in underground," Journal of the Korean Geoenvironmental Society, vol. 19, no. 10, pp. 27-34, 2018.

[17] D. E. Daniel and R. M. Koerner, Quality Assurance and Quality Control for Waste Containment Facilities, U. S. Environmental Protection Agency, Washington, DC, USA, 1993.

[18] A. Khandelwal and A. J. Rabideau, "Enhancement of soil-bentonite barrier performance with the addition of natural humus," Journal of Contaminant Hydrology, vol. 45, no. 3-4, pp. 267-282, 2000.

[19] E. Guler, H. O. Ozhan, and S. Karaoglu, "Hydraulic performance of anionic polymer-treated bentonite-granular soil mixtures," Applied Clay Science, vol. 157, pp. 139-147, 2018.

[20] Y. L. Yang, K. R. Reddy, Y. J. Du, and R. D. Fan, Sodium Hexametaphosphate (SHMP)-amended Calcium Bentonite for Slurry Trench Cutoff Walls: Workability and Microstructure Characteristics, NRC Research Press, Ottawa, Canada, 2017.

[21] A. Norris, G. D. Emidio, M. A. Malusis, and M. Replogle, "Modified bentonites for soil-bentonite cutoff wall applications with hard mix water," Applied Clay Science, vol. 158, pp. 226-235, 2009.

[22] Y. Wang, Y. Chen, H. Xie, C. Zhang, and L. Zhan, "Lead adsorption and transport in loess-amended soil-bentonite cut-off wall," Engineering Geology, vol. 215, pp. 69-80, 2016.

[23] S. Agarwal and A. Rani, "Adsorption of resorcinol from aqueous solution onto ctab/naoh/flyash composites: equilibrium, kinetics and thermodynamics," Journal of Environmental Chemical Engineering, vol. 5, no. 1, pp. 526-538, 2017.

[24] U. Habiba, T. A. Siddique, T. C. Joo, A. Salleh, B. C. Ang, and A. M. Afifi, "Synthesis of chitosan/polyvinyl alcohol/zeolite composite for removal of methyl orange, Congo red and chromium (vi) by flocculation/adsorption," Carbohydrate Polymers, vol. 157, pp. 1568-1576, 2017.

[25] R. Zhu, T. Wang, J. Zhu, F. Ge, P. Yuan, and H. He, "Structural and sorptive characteristics of the cetyltrimethylammonium and polyacrylamide modified bentonite," Chemical Engineering Journal, vol. 160, no. 1, pp. 220-225, 2010.

[26] Y. C. Wang, G. Z. Dai, X. S. Jiang, and G. C. Shi, "Research on performance of impervious grouting based on modified bentonite," Water Resource and Power, vol. 33, no. 6, pp. 123-125, 2015.

[27] T. Tong, Z. F. Zhang, Y. C. Lu, and J. J. Zhang, "Swelling and mechanical behavior of poly (vinyl alcohol)/bentonite hybrid hydrogels," The Chinese Journal of Process Engineering, vol. 10, no. 3, pp. 503-506, 2006.

[28] N. B. Singh and S. Rai, "Effect of polyvinyl alcohol on the hydration of cement with rice husk ash," Cement and Concrete Research, vol. 31, no. 2, pp. 239-243, 2001.

[29] H. Shao, X. L. Liu, Y. J. Li, and J. Ding, "Study on the adsorption behavior of modified-bentonite to oily pollutant," Acta Scientiae Circumstantiae, vol. 35, no. 7, pp. 2114-2120, 2015.

[30] G. Dai, W. Shi, X. Jiang, G. Shi, and Y. Zhang, "Study on the antiseepage mechanism of the PBFC slurry for landfill site," International Journal of Modern Physics B, vol. 31, no. 16-19, Article ID 1744087, 2017.

[31] G. Dai, Y. Sheng, S. Li, and Y. Zhang, "Experimental study on mechanical properties of anti-seepage slurry in landfill," Modern Physics Letters B, vol. 32, no. 34, Article ID 1840065, 2018.
[32] M. G. Lee, C. T. Chiu, and Y. C. Wang, "The study of bond strength and bond durability of reactive powder concrete," Journal of Astm International, vol. 2, no. 7, p. 10, 2005.

[33] T. L. T. Zhan, C. Guan, H. J. Xie, and Y. M. Chen, "Vertical migration of leachate pollutants in clayey soils beneath an uncontrolled landfill at huainan, China: a field and theoretical investigation," Science of The Total Environment, vol. 470-471, pp. 290-298, 2014.

[34] Y. Pan, J. Yi, S.-H. Goh, J. Hu, W. Wang, and Y. Liu, "A three-dimensional algorithm for estimating water-tightness of cement-treated ground with geometric imperfections," Computers and Geotechnics, vol. 115, Article ID 103176, 2019.

[35] Y. Pan and Y. Fu, "Effect of random geometric imperfections on the water-tightness of diaphragm wall," Journal of $\mathrm{Hy}$ drology, vol. 580, Article ID 124252, 2020.

[36] S. H. Chew, A. H. M. Kamruzzaman, and F. H. Lee, "Physicochemical and engineering behavior of cement treated clays," Journal of Geotechnical and Geoenvironmental Engineering, vol. 130, no. 7, pp. 696-706, 2004.

[37] J. Locat, H. Trembaly, and S. Leroueil, "Mechanical and hydraulic behaviour of a soft inorganic clay treated with lime," Canadian Geotechnical Journal, vol. 33, no. 4, pp. 654-669, 1996.

[38] C. Xu, Z. Wang, Y. He, X. Li, and F. Bai, "Sensitivity analysis of the numerical study on the thermal performance of a packedbed molten salt thermocline thermal storage system," Applied Energy, vol. 92, pp. 65-75, 2012.

[39] X. Huang, K. Xiao, and Y. Shen, "Recent advances in membrane bioreactor technology for wastewater treatment in China," Frontiers of Environmental Science \& Engineering in China, vol. 4, no. 3, pp. 245-271, 2010a.

[40] Y. Y. Huang, G. F. Chen, B. Liu, and L. R. Su, "Research progress on contents, speciation and transformation of heavy metals in livestock and poultry manures," Guangxi Agricultural Sciences, vol. 10, 2010b.

[41] M. Hassan and B. Xie, "Use of aged refuse-based bioreactor/ biofilter for landfill leachate treatment," Applied Microbiology and Biotechnology, vol. 98, no. 15, pp. 6543-6553, 2014. 


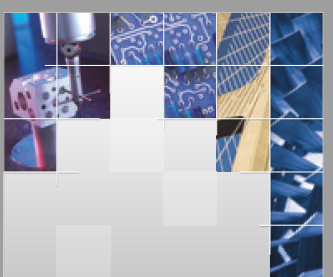

\section{Enfincering}
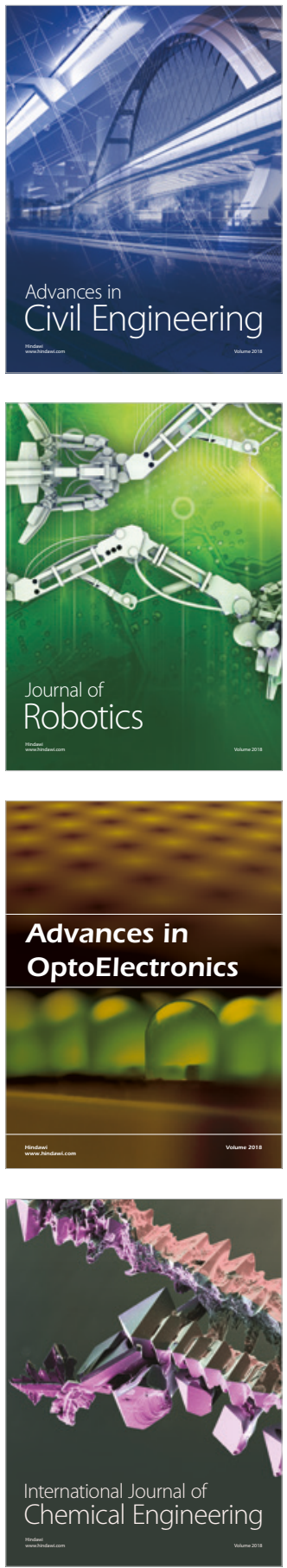

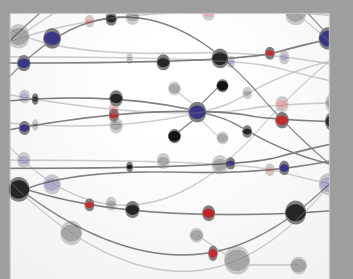

\section{Rotating \\ Machinery}

The Scientific World Journal

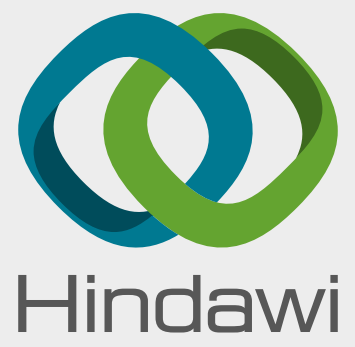

Submit your manuscripts at

www.hindawi.com
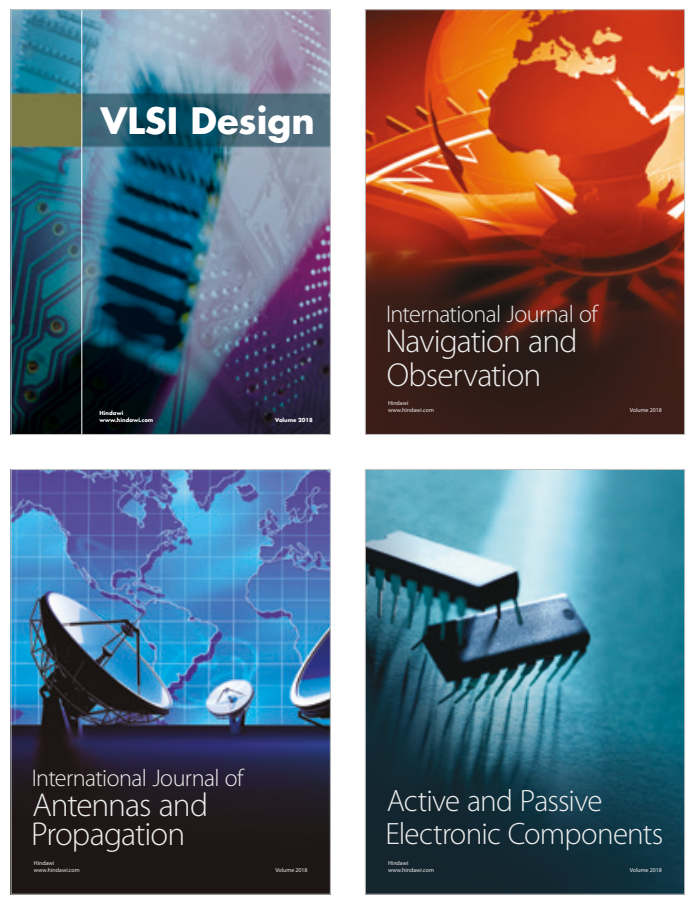
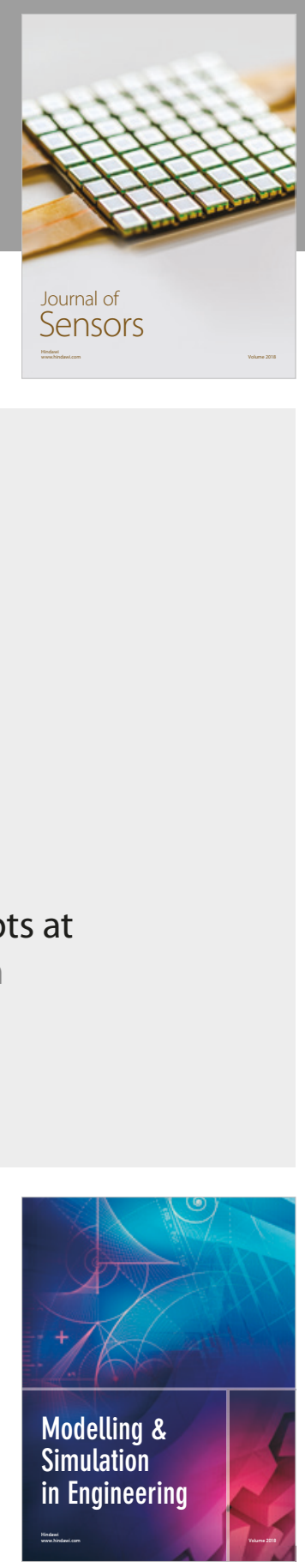

\section{Advances \\ Multimedia}
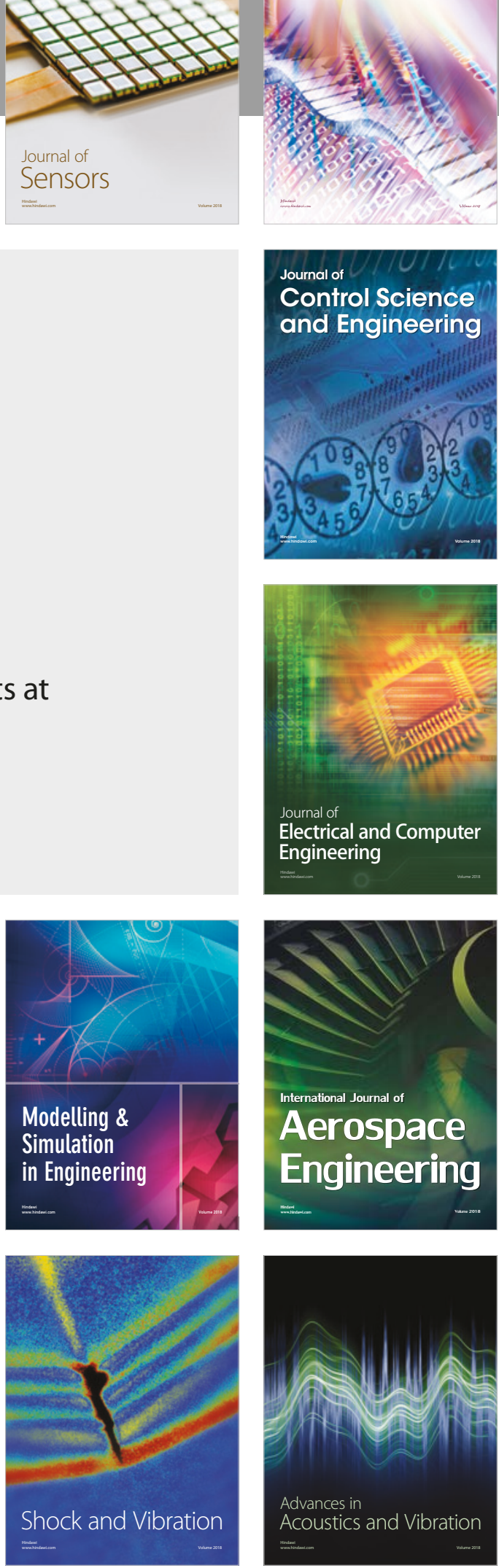